\section{Case Reports in Ophthalmology}

\title{
Giant Orbital Melanoma in a Heroin Abuser
}

\author{
Alena Furdova ${ }^{\mathrm{a}}$ Pavel Babal $^{\mathrm{b}}$ \\ ${ }^{a}$ Department of Ophthalmology, Faculty of Medicine, Comenius University, \\ Bratislava, Slovakia; ${ }^{b}$ Department of Pathology, Faculty of Medicine, Comenius University, \\ Bratislava, Slovakia
}

\section{Keywords}

Uveal melanoma · Orbital extension · Extraorbital extension · Heroin abuser

\begin{abstract}
Purpose: The aim of this report was to report a heroin abuser with nondiagnosed giant uveal melanoma infiltrating the orbit and prolapsing through the face. Methods: We conducted a case report of the patient with giant melanoma. Results: In March 2013, a 39-year-old male with bleeding from the right side of his face was taken to the Emergency Center of the University Hospital Bratislava by ambulance. The heroin abusing, homeless male who had never been treated before reported a 2-year history of a prolapsed, dark colored mass from his eye. Acute computed tomography confirmed a solid mass $20 \times 20 \mathrm{~cm}$ prolapsing from the orbit. The patient rejected primary care, accepted only 1 transfusion and left the hospital. Two months later, he was admitted to the hospital due to anemia after many collapses. Liver metastasis was present. Surgical palliative therapy was not possible due to his general status. The patient started fractionated external radiotherapy with $8.0 \mathrm{~Gy} \mathrm{Co}{ }^{60}$. Histopathological examination of the biopsy specimen showed malignant melanoma of the epitheloid type G23. The patient died in December 2013. Conclusion: Extraorbital formation of a melanoma mass may progress to a giant volume, and without treatment, led to metastases in the liver and to death after 9 months in our patient with anemia.




\section{Case Reports in Ophthalmology}

\section{Introduction}

Uveal melanoma is the most aggressive type of primary intraocular malignancy in adults. Primary orbital melanoma is exceedingly rare and is estimated to account for less than $1 \%$ of all orbital tumors in most large series. The vast majority of orbital melanomas are either metastatic or represent extension from skin and conjunctival melanomas or orbital infiltration from uveal melanoma; T4 stage is rare. Distinguishing primary orbital melanoma from metastatic orbital melanoma or extension from adjacent structures is essential because the treatment for primary melanoma of the orbit is usually orbital exenteration, whereas exenteration would only be appropriate as a palliative measure in cases of metastasis or extension from adjacent orbital structures [1, 2].

Age and volume (size) of the tumor have been shown to be prognostic indicators following therapy for uveal melanoma.

Choroidal melanoma has a well-documented capacity to metastasize hematogenously. The liver is the most common site of metastatic disease $[3,4]$.

\section{Case Presentation}

In March 2013, a 39-year-old male was taken to the Emergency Center of the University Hospital by ambulance with bleeding from the right side of his face. The heroin abusing, homeless male who had never been treated before reported a 2-year history of a prolapsed, dark colored mass from his eye (Fig. 1a-c). Computed tomography confirmed a solid mass $20 \times 20 \mathrm{~cm}$ prolapsing from the orbit (Fig. 2). The patient rejected systemic care, accepted only 1 transfusion and left hospital. Two months later, he was admitted to the hospital due to anemia after many collapses. There was presence of liver metastasis. The patient again accepted only first aid and left the hospital after 1 or 2 days. Histopathological examination of the biopsy specimen showed malignant melanoma of the epitheloid type G2-3 with necrotic spaces, S100+, HMB45+, MelanA+, cyclin D1 -, p53-, Bcl2+ 20\%, Ki67+ 30\%, with poor prognosis (Fig. 3). The tumor mass increased its volume on the right side; visual acuity in the left eye was 20/20. In September 2013, the interval between collapses was shortened to 1 week, and the patient decided to start treatment with the help of a psychologist and a social worker. Surgical palliative therapy was not possible due to his general status and anemia, and he started fractionated external radiotherapy, accepting only one $8.0 \mathrm{~Gy} \mathrm{Co} \mathrm{Co}^{60}$ fraction. He was HIV negative. In October 2013, his general status was very poor (Fig. 1d-f). The patient died in December 2013.

\section{Discussion}

Important prognostic factors for death from metastatic melanoma include the size of the tumor (the larger the tumor, the worse the prognosis), the location of the tumor, the age of the patient at the time of diagnosis (the older the patient, the worse the short-term survival prognosis), and extrascleral tumor extension. However, questions have been raised regarding the efficacy of irradiation treatment in limiting metastatic spread of the tumor. Overall rates of metastatic disease are comparable to those observed after enucleation; thus, enucleation should be limited to patients with large tumors in whom the eye is unlikely to be salvaged by irradiation. Melanomas of the orbit are rare and generally occur in patients with 
disseminated metastases during the terminal stages of the disease, with a short life expectancy. Treatment is palliative and, among the various possible treatment options, circumscribed proton beam radiotherapy or global photon beam radiotherapy, at relatively high irradiation doses, seem to achieve the most favorable results [5-7].

Our patient demonstrated the fatal outcome of nontreated melanoma in heroin abusers. His status was associated with a number of serious health conditions such as infection of the lining of the heart and valves, anemia, abscesses, constipation, gastrointestinal cramping, and liver metastases.

\section{Statement of Ethics}

This article does not include results of experimental investigations on human subjects. The present research complies with the guidelines for human studies.

\section{Disclosure Statement}

The authors declare no financial disclosure and no conflicts of interest.

\section{References}

1 Shields CL, Shields JA: Ocular melanoma: relatively rare but requiring respect. Clin Dermatol 2009;27:122-133.

-2 Tellado M, Specht CS, McLean IW, Grossniklaus HE, Zimmerman LE: Primary orbital melanomas. Ophthalmology 1996;103:929-932.

-3 Polito E, Leccisotti A: Primary and secondary orbital melanomas: a clinical and prognostic study. Ophthal Plast Reconstr Surg 1995;11:169-181.

-4 Singh AD, Turell ME, Topham AK: Uveal melanoma: trends in incidence, treatment, and survival. Ophthalmology 2011;118:1881-1885.

5 (COMS) Collaborative Ocular Melanoma Study Group: Assessment of metastatic disease status at death in 435 patients with large choroidal melanoma in the COMS. COMS Report No.15. Arch Ophthalmol 2001;119:670-676.

6 Seddon JM, Gragoudas ES, Egan KM, et al: Relative survival rates after alternative therapies for uveal melanoma. Ophthalmology 1990;97:769-777.

7 Grossniklaus HE: Progression of ocular melanoma metastasis to the liver. JAMA Ophthalmol 2013;131:462-469. 


\section{Case Reports in Ophthalmology}

\begin{tabular}{l|l}
\hline Case Rep Ophthalmol 2017;8:288-293 \\
\hline DOI: 10.1159/000475521 & $\begin{array}{l}\text { @ 2017 The Author(s). Published by S. Karger AG, Basel } \\
\text { www.karger.com/cop }\end{array}$ \\
\hline
\end{tabular}

Furdova and Babal: Giant Orbital Melanoma in a Heroin Abuser
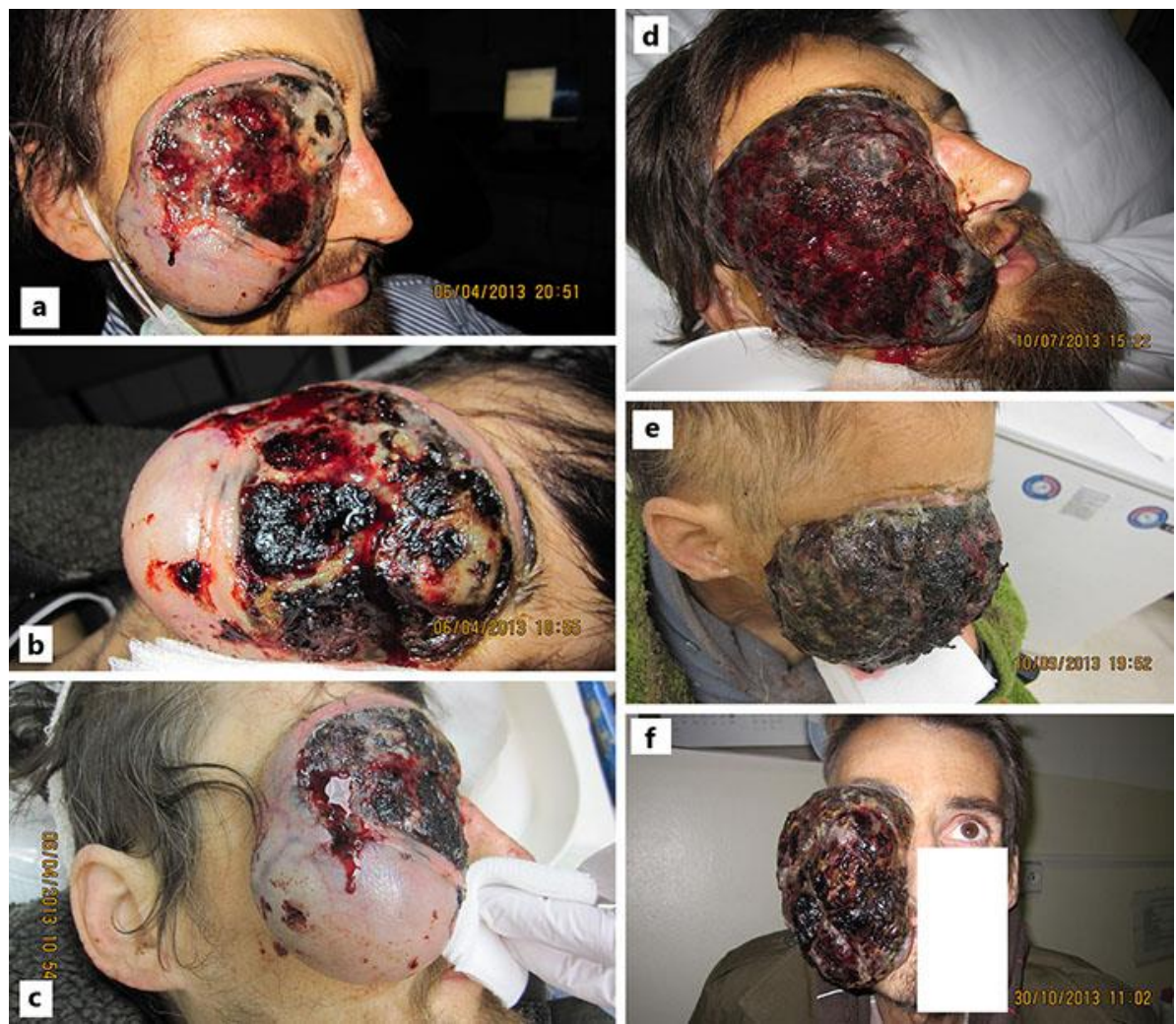

Fig. 1. a The patient in April 2013 with a prolapsed, bleeding tumor mass. b Details of the tumor mass with temporal skin socket. c Details of the temporal part of the mass. $\mathbf{d}$ The patient in July 2013 with an enlarged tumor mass and bleeding. e The patient in September 2013 before external $\mathrm{Co}^{60}$ radiotherapy. $f$ The patient in October 2013 after external $\mathrm{Co}^{60}$ radiotherapy. 


\begin{tabular}{|c|c|c|}
\hline \multirow{2}{*}{$\begin{array}{r}\text { Case Reports in } \\
\text { Ophthalmology }\end{array}$} & \multicolumn{2}{|c|}{ Case Rep Ophthalmol 2017;8:288-293 } \\
\hline & DOI: $10.1159 / 000475521$ & $\begin{array}{l}\text { ( } 2017 \text { The Author(s). Published by S. Karger AG, Basel } \\
\text { www.karger.com/cop }\end{array}$ \\
\hline
\end{tabular}
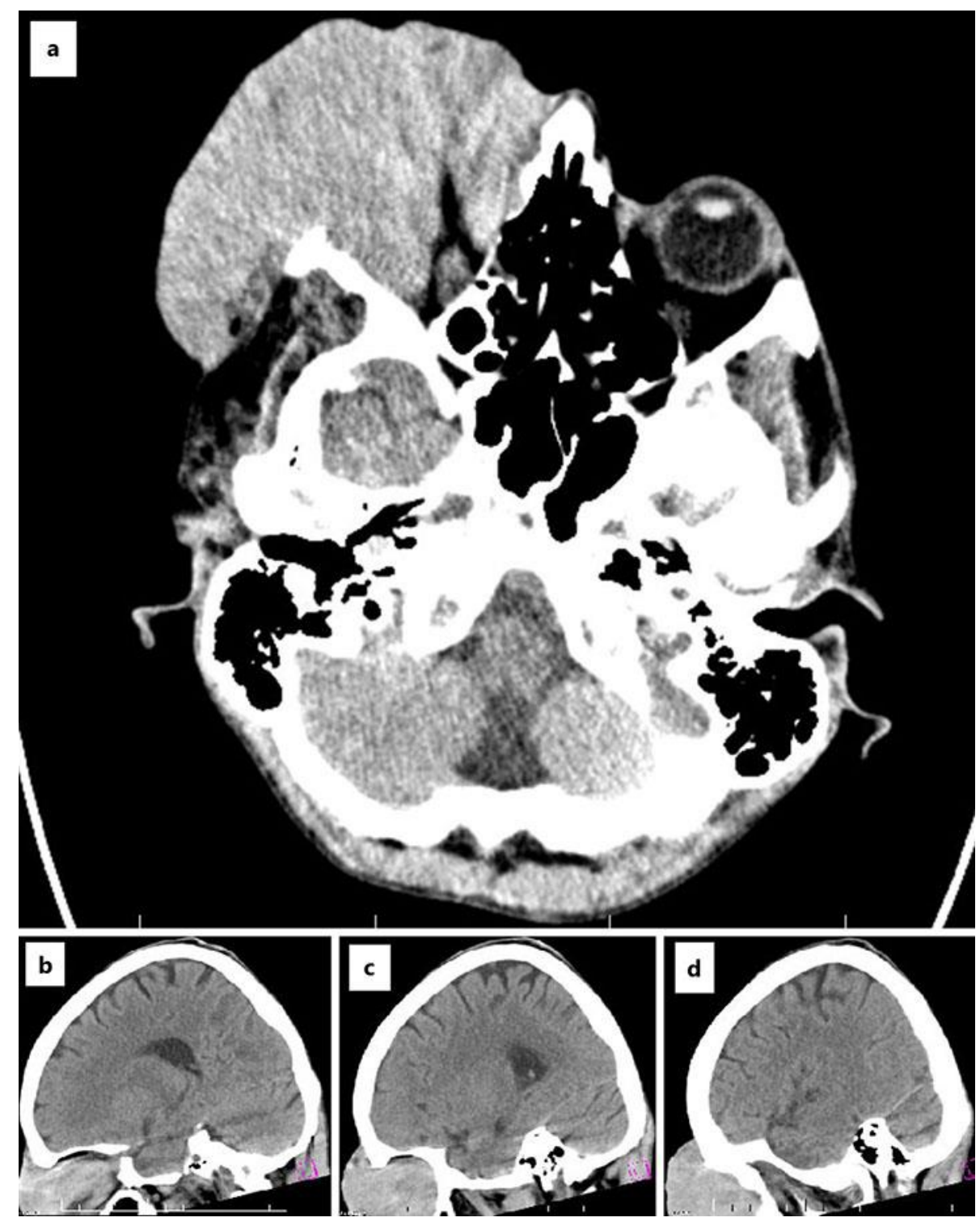

Fig. 2. a Axial orbital computed tomography of the orbital prolapsed mass without infiltration of the skull. b-d Sagittal computed tomography of the mass infiltrating the orbital cone. 


\section{Case Reports in Ophthalmology}

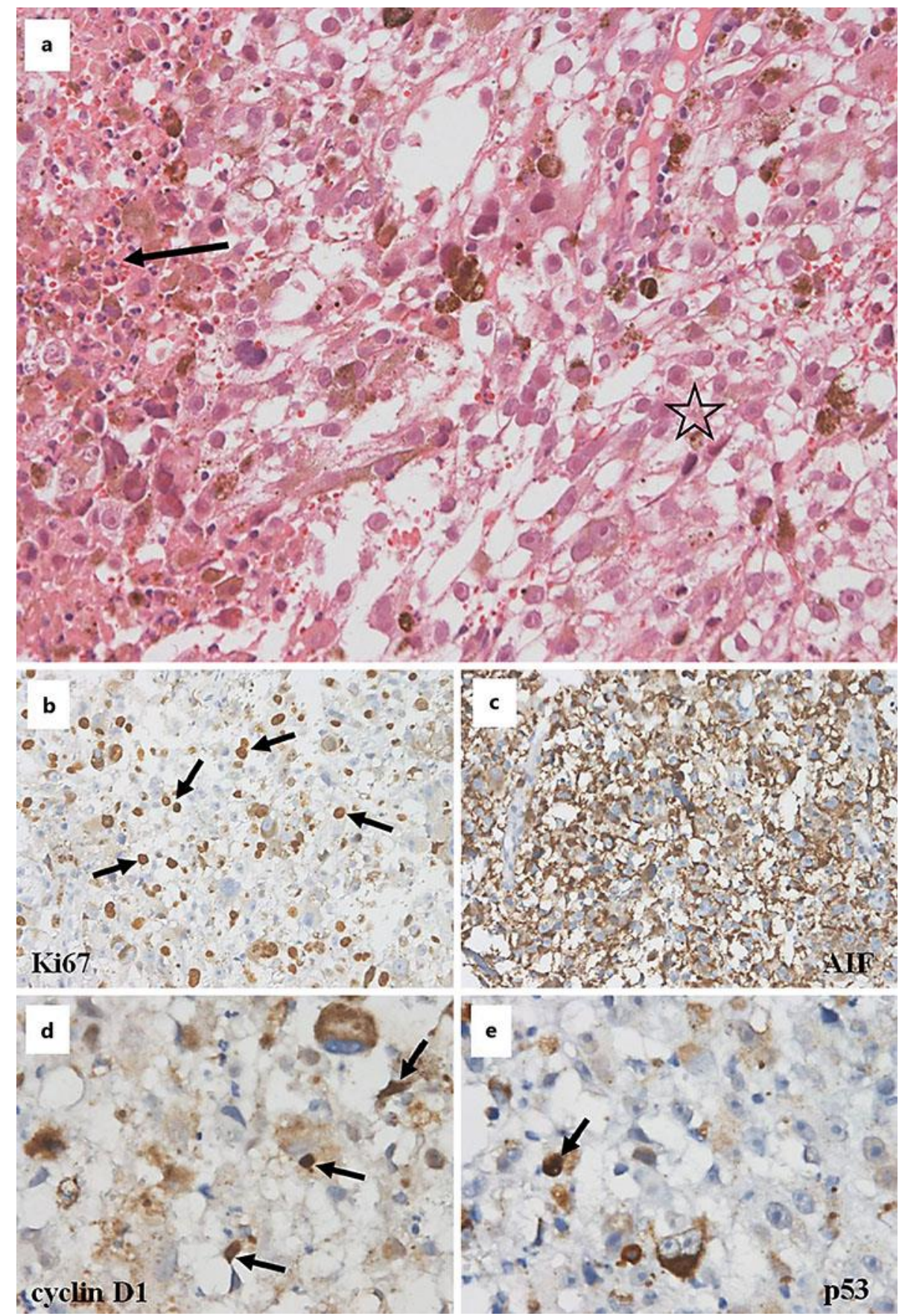

Fig. 3. a Microscopic picture of the tumor composed of epithelioid melanocytes (star), with large areas of necrosis (arrow). b Immunohistochemical detection of some prognostic factors expressed in the tumor (high proliferation index Ki67 [positive nuclei, arrows]). c Diffuse strong cytoplasmic positivity of apoptosis-inducing factor. $\mathbf{d}$ Few cyclin D1-positive nuclei (arrows). e Odd p53-positive nucleus (arrow). Hematoxylin and eosin. $\times 200$ (a). Immunoperoxidase, diaminobenzidine, $\times 200 / 400(b-e)$. 